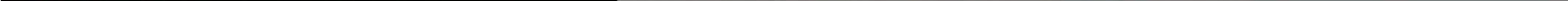




\section{DISCLAIMER}

This report was prepared as an account of work sponsored by an agency of the United States Government. Neither the United States Government nor any agency Thereof, nor any of their employees, makes any warranty, express or implied, or assumes any legal liability or responsibility for the accuracy, completeness, or usefulness of any information, apparatus, product, or process disclosed, or represents that its use would not infringe privately owned rights. Reference herein to any specific commercial product, process, or service by trade name, trademark, manufacturer, or otherwise does not necessarily constitute or imply its endorsement, recommendation, or favoring by the United States Government or any agency thereof. The views and opinions of authors expressed herein do not necessarily state or reflect those of the United States Government or any agency thereof. 


\section{DISCLAIMER}

Portions of this document may be illegible in electronic image products. Images are produced from the best available original document. 
UCR L- 8030

Physics distribution

\author{
UNIVERSITY OF CALIFORNIA \\ Radiation Laboratory \\ Berkeley, California \\ Contract No. W-7405-eng-48
}

DATA FOR ELEMENTARY-PARTICLE PHYSICS

Walter H. Barkas and Arthur H. Rosenfeld

March 20, 1958

Printed for the U.S. Atomic Energy Commission 
This report was prepared as an account of Government sponsored work. Neither the United States, nor the Commission, nor any person acting on behalf of the Commission:

A. Makes any warranty or representation, express or implied, with respect to the accuracy, completeness, or usefulness of the information contained in this report, or that the use of any information, apparatus, method, or process disclosed in this report may not infringe privately owned rights; or

B. Assumes any liabilities with respect to the use of, or for damages resulting from the use of any information, apparatus, method, or process disclosed in this report.

As used in the above, "person acting on behalf of the Commission" includes any employee or contractor of the Commission to the extent that such employee or contractor prepares, handles or distributes, or provides access to, any information pursuant to his employment or contract with the Commission. 


\title{
DATA FOR ELEMENTARY-PARTICLE PHYSICS
}

\author{
Walter H. Barkas and Arthur H. Rosenfeld \\ Radiation Laboratory \\ University of California \\ Berkeley, California \\ March 20, 1958
}

Elementary-particle data and certain other reference information frequently are needed by research workers in hi;n-enerry physics in a compact and readily accessible form. For the use of students and staff members in the Radiation Laboratory we have attempted to meet this need. In this summary we have tried to employ units and concepts natural to this field, and to drop those that are irrelevant or obsolete. Slightly older versions of Tables I and Va have already appeared in Gell-Mann's and Rosenfeld's review of elementary particles. 1

The tables and graphs are as follows:

Table I. The masses and mean lives of the elementary particles

Two international congresses have recently been held on elementaryparticle physics: the 1957 Rochester Conference, and the Padova-Venezia Congress. At each, important new data on particle masses and mean lives were presented. In addition, the masses of many particles are better known because an accurate range-energy relation ${ }^{2}$ for nuclear track emulsion has now been set forth, so that the errors in decay energies have been greatly reduced. Moreover, it appears that the existence of a single $\mathrm{K}$ particle and its antiparticle, with a common mass and decay lifetime, may be reasonably zssumed. Bubble chambers and well-calibrated emulsion stacks have provided reliable new data on $\Lambda$ - and $\Sigma$-hyperon decay energies and lifetimes.

All these considerations suggest that enough may now be known about the masses and lifetimes of most of the known elementary particles to warrant compilation.

The best values of the masses and mean lives of nucleons, leptons (e and $\mu$ ), and pions have been computed recently by Cohen, Crowe, and DuMond; ${ }^{3}$ we have used their values directly. We have also used their values

\footnotetext{
M. Gell-Mann and A.H. Rosenfèld, Ann. Rev. Nuclear Sci. 7, 407 (1957). ¿Barkas, Barrett, Cüer, Heckman, Smith, and Ticho, The Range-Energy Relation in Emulsion. Part 1. Range Measurements, UCR L-3768, April 1957 ;

Walter H. Barkas, The Range-Energy Relation in Emulsion. Part 2. The Theoretical Range, UCRL-3769, April 1957.

${ }^{3}$ Cohen, Crowe, and DuMond, Fundamental Constants of Physics (Interscience, New York, 1957).
} 
for the masses of proton and pions in obtaining the masses (and uncertainty in mass) of strange particles from the experimental $Q$ values. It is interesting to note that with the single exception of the mass differences in the $\Sigma$-hyperon triplet, it is now the uncertainties in the pion mass and the range-energy relation in emulsion that contribute almost all the uncertainty to the strange particle masses. If there are theoretical questions that require a further reduction (by an order of magnitude) of the errors in the masses, methods other than the measurement of ranges in emulsion probably should be devised, both for determining strange-particle decay energies and for better determining the masses of $\pi$ and $\mu$ mesons. Range straggling and uncertainties of the local density of even carefully calibrated emulsions limit the practically attainable accuracy of range measurements and the fundamental range-energy calibration curve itself.

Our recommended values of masses and mean lives are given for all the elementary particles on which data are available. The sources of the information are listed as references. When systematic as well as statistical errors appear to affect a measurement, we have been forced to exercise jud $\xi$ ment, but this has in no case had a very important effect on the result. This table is not intended to take the place of the critical review by Henri, Shapiro, and $\mathrm{Way}^{4}$ of all the experiments undertaken so far.

The observed particle spins suggest the following generalization: the particles listed as leptons and baryons have spin $1 / 2$; the mesons have spin zero.

The $\Sigma^{-}$mass is derived entirely from the $\Sigma^{-}-\Sigma^{+}$mass difference measured in emulsion.

To avoid skewed distributions in calculating weighted averages of lifetimes, we have always converted first to decay rates.

4tHenri, Shapiro, and Way, to be published in Revs. Modern Phys. 
Table I

Masses and mean lives of elementary particles; November, 1957

(The antiparticles are assumed to have the same spins, masses, and mean lives as the particles listed)

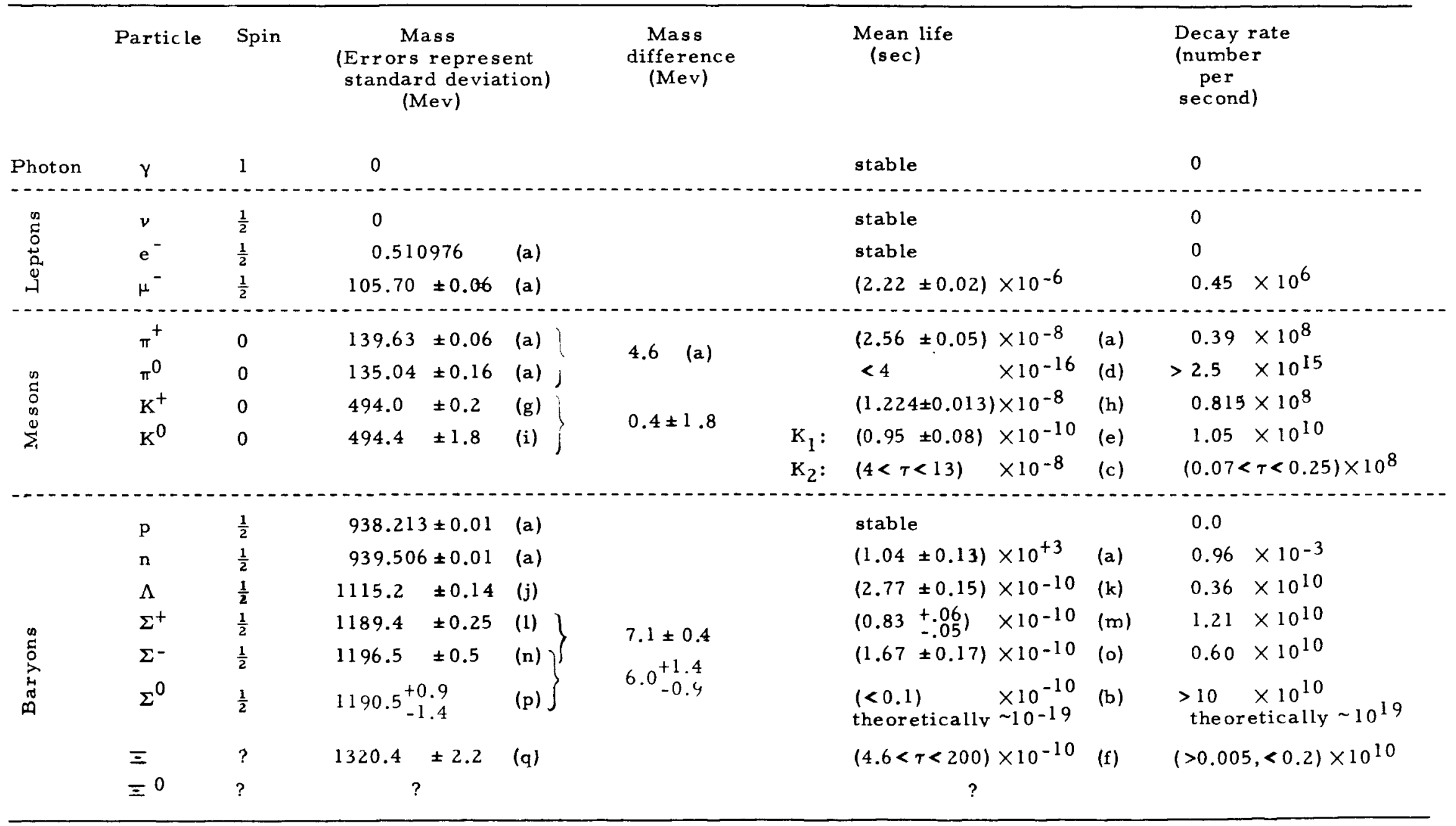


(a) From compilations by Cohen, Crowe, and DuMond, Nuovo cimento 5, 541 (1957), and Fundamental Constants of Physics, to be published by Interscience, New York, 1957. They include all data avallable before January 1, 1957

(b) Alvarez, Bradner, Falk-Varant, Gow, Rosenfeld, Solmitz, and Tripp, K- Interactions in Hydrogen, UCR L-3775, May 1957.

(c) Landé, Lederman, Bardon, Tinlot, and Chinowsky (to be published).

(d) Orear, Harris, and Taylor, Phys. Rev. 106, 327 (1957)

(e) Eisler, Plano, Samios, Schwartz, and Steinberger, Nuovo cimento 5, 1700 (1957)

(f) G H Trilling and G. Neugebauer, Phys. Rev. 104, 1688 (1956).

(g) $\mathrm{M}_{\mathrm{K}}^{+}=3 \mathrm{~m}_{\pi}^{ \pm}+Q_{\gamma}$, where $Q_{\tau}$ is the weighted average of values reported by Heckman, Smith, and Barkas, Nuovo cimento 4 , $5 \mathrm{l}^{\mathrm{K}}$ (1956), Roy Haddock, Nuovo cimento 4, 240 (1956), and Bacchella, Berthelot, et al., Nuovo cimento 4, 1529 (1956) The uncertainty in $\mathrm{m}_{\mathrm{p}}$ has of course been treated as common to all experiments We have as sumed that the $\mathrm{K}^{-} 1 \mathrm{~s}$ the antIparticle of the $\mathrm{K}^{\mathrm{T}}$ and shares the same mass and lifetime. The present experimental mass of the $\mathrm{K}^{-}$is consistent with this assumption, namely 493.4 $\pm 0.5 \mathrm{Mev}$ (R.S White, compilation of all emulsion data for $1957 \mathrm{Rochester} C$ onference)

(h) $\mathrm{T}_{\mathrm{K}}{ }^{+}$, from weighted average of the decay rates corresponding to the following mean hives.

$1.227 \pm 0.015 \times 10^{-8} \mathrm{sec}$ (Alvarez, Crawford, Good, and Stevenson, Phys Rev. (to be published))

$1.211 \pm 0.026 \times 10^{-8}$ sec (V. Fitch and R. Motley, Phys. Rev. 101, 496 (1956), Phys. Rev 105, 265 (1957) and

private communication.) The quoted errors are statistical only. We have assumed that the $\mathrm{K}^{-}$is the antiparticle of

the $\mathrm{K}^{+}$and shares the same mean life. The present experimental mean life is consistent with this assumption, namely $\tau_{K^{-}}=1.25 \pm 0.11 \times 10^{-8} \sec (W . H$. Barkas, 1957 Rochester Conference).

(1) $\mathrm{m}_{K^{0}}$, weighted average of the following $Q$ values for $\mathrm{K}^{0} \rightarrow \pi^{+}+\pi^{-+} Q$ (Mev):

$214.0 \pm 2.5$ (Thompson, Burwell, and Huggett, Nuovo cimento 4, Suppl. 3, 286 (1956)),

$212.0 \pm 4$ (Arnold, Martin, and Wyld, Phys Rev. 100, 1545, 71955)),

$217.0 \pm 4$ (R. Armenteros, 1957 Rochester Conference),

$222.6 \pm 5.3$ (Fretter, Freisen, and Lagarrique, Nuovo cimento 4, Suppl. 3, 539 (1956))

(J) $\mathrm{m}_{\Lambda}$ is the weighted average (in Mev) of:

$1114.00 \pm 0.39$ (all cloud chamber work in review by Cohen et al.),

$1115.74 \pm 0.40$ ( $R$. Armenteros, 1957 Rochester Conference),

$1115.30 \pm 0.16$ (W. H. Barkas, Padua-Venice Conference, 1957).

There is another value, $m=1114.7 \pm 0.21 \mathrm{Mev}$, reported by Friedlander et al. in Phil. Mag. 45, 533 (1957)

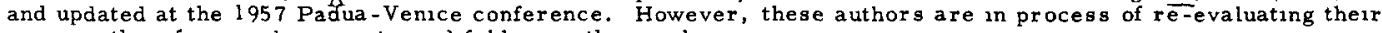
errors, therefore we have postponed folding in their value.

(k) $\tau_{\Lambda}$, from weighted average of the decay rates corresponding to the following mean lives.

$1.9 \pm 0.4 \times 10^{-8} \mathrm{sec}$ (Graves, Brown, Glaser, and Perl, Bull. Am. Phys. Soc. 2, 221 (1957)),

$2.77 \pm 0.2 \times 10^{-8} \sec (e)$

$3.1 \pm 0.5 \times 10^{-8} \sec (\mathrm{b})$

$3.25 \pm 033 \times 10^{-8} \sec (\mathrm{a})$

(l) $m_{\Sigma}{ }^{+}$, weighted average (allowing for common systematic uncertainties) of

l I $89.28 \pm 0.28 \mathrm{Mev}$ (W.H Barkas, 1957 Padua-Venice Conference),

$1189.1 \pm 0.4 \mathrm{Mev}$ (Fry, Schneps, Snow, and Swam1, Phys. Rev. (to be published)),

$11903 \pm 0.5 \mathrm{Mev}(\mathrm{R} S$ White, 1957 Rochester Conference)

(m) $\tau_{\Sigma}+$ from weighted average of

$0.95 \pm 0.30 \times 10^{-10} \sec (G r a v e s$ et al., Bull. Am. Phys Soc. 2, $221(1957)$ ),

$069 \pm 0.10 \times 10^{-10} \mathrm{sec}(\mathrm{b})$,

$0.90+0.10 \times 10^{-10} \mathrm{sec}$ (average of emulsion data on the protonic decay mode onlv). The er - un data include 15 decay

events from Rochester and 14 from Wisconsin that were compiled by Dr. G Snow for the 1957 Rochester Conference

Included also are 12 events by Glasser, Seeman, and Snow (private communication, Nov 13, 1957) and 59 from the University of California Thesis of P C. Giles, reported at the Padua-Venice Conference by $W$ H Barkas.

(n) $m_{\Sigma}$ from the following $m_{\Sigma}-m_{\Sigma}+$ mass differences:

$6.56 \pm 0.66$ Mev(Barkas, Giles, Heckman, Inman, Mason, and Smith, Hyperon and K--Meson Masses, UCRL-3892, Sept. 1957), $7.10 \pm 0.92 \mathrm{Mev}$ (Chupp, Goldhaber, Goldhaber, and Webb)

$8.12 \pm 148 \mathrm{Mev}(\mathrm{Fry}, \mathrm{Schneps,} \mathrm{Snow,} \mathrm{Swamz,} \mathrm{and} \mathrm{Wold,} \mathrm{Phys.} \mathrm{Rev} \mathrm{104,} 270$ (1956)

$7.46 \pm 0.72 \mathrm{Mev}(\mathrm{K}$ Gollaboration-Presented by Prowse at Padua-Venice Conference, 1957)

(o) $\tau_{\Sigma-,}$, weighted average of

$1.9_{-0.3}^{+0.4} \times 10^{-10} \mathrm{sec}(C o l u m b 1 a$, Bologna, Pisa propane chamber collaboration (Padua-Venice Conference, 1957))

$16 \pm 02 \times 10^{-10} \mathrm{sec}(\mathrm{b})$

(p) $\Sigma^{0}$ from weighted average of

$1136.0^{+3} 8$ Alvarez et al. "Interactions of $\mathrm{K}^{-}$Mesons in Hydrogen" UCRL-3775, (1957)

$1192.6 \pm 3.5$ Ersler et al "Associated Production of $\Sigma^{0}$ and $\theta,{ }^{0}$, Mass of the $\Sigma^{0}$ " Nevis-60 Report R-198 (1957)

$1191.6 \pm 3.3 \mathrm{M}$. L Stevenson "The $\Sigma^{0}$ Mass" UCRL-8199 (1958). This experiment was performed since Table V was prepared. The older $\Sigma^{0}$ mass of 1190.0 was used to calculate Table $\mathrm{V}$.

(q) $\mathrm{m}=$ - from 12 events. Six of these (from CalTech) are summarized by Trilling and Neugebauer, (f), six others are compiled from Tables $4-15$ by Cohen, Crowe, and DuMond. 
Table II. Atomic and nuclear properties of materials

Atomic and nuclear properties of materials often used as particle absorbers and detectors have been collected for ready reference. The densities given are subject to variations depending on the for $m$ in which the material has been prepared. This is an especially important variable for graphite. The radiation length, as is well known, depends on the approximations made in its calculation.

In Table II, for definiteness and consistency, we have preferred simply to take the values quoted by Bethe and Ashkin. 5 These have not been corrected for the failure of the Born approximation, and Wheeler's and Lamb's 6 calculation of the $\zeta$ was used $(\zeta$ is the efficiency for bremsstrahlung of electrons relative to nuclei in a screened field). Wheeler and Lamb calculated $\zeta$ on the basis of a Thomas-Fermi model of the atom and neglected electron exchange. The failure of the Born approximation is known to cause the tabulated radiation length to be about $10 \%$ too low for lead, 7 and the error varies approximately with the square of the atomic number, so that the effect in emulsion, for example, is about 3\%. The effects of the other approximations are not well known. The calculated radiation length is particularly uncertain in liquid hydrogen. A rough formula useful when the atomic number, $Z$, exceeds 5 is

$$
\mathrm{L}_{\mathrm{rad}} \approx 166 \mathrm{z}^{-0.76} \mathrm{~g} / \mathrm{cm}^{2} \text {. }
$$

${ }^{5} \mathrm{H}$. Bethe and J. Ashkin, Part II of Experimental Nuclear Physics, E。 Segrè, Ed. (Wiley, New York, 1953).

Professor W。K. H. Panofsky has kindly advised us regarding the various types of errors in the calculation of the radiation length, and if another edition of these tables is written, it may be possible to refine these numbers somewhat and to include suggested changes of other sorts.

6 J.A. Wheeler and W。E.Lamb, Phys。Rev。 55, 858 (1939).

7

7 Davies, Bethe, and Maximom, Phys。Rev。93, 788 (1954)。 
Table II

Atomic and nuclear properties $(\mathrm{dE} / \mathrm{d} \mathbf{x}$, collision mean free path,

radiation length, etc.) of materials used as absorbers and detectors

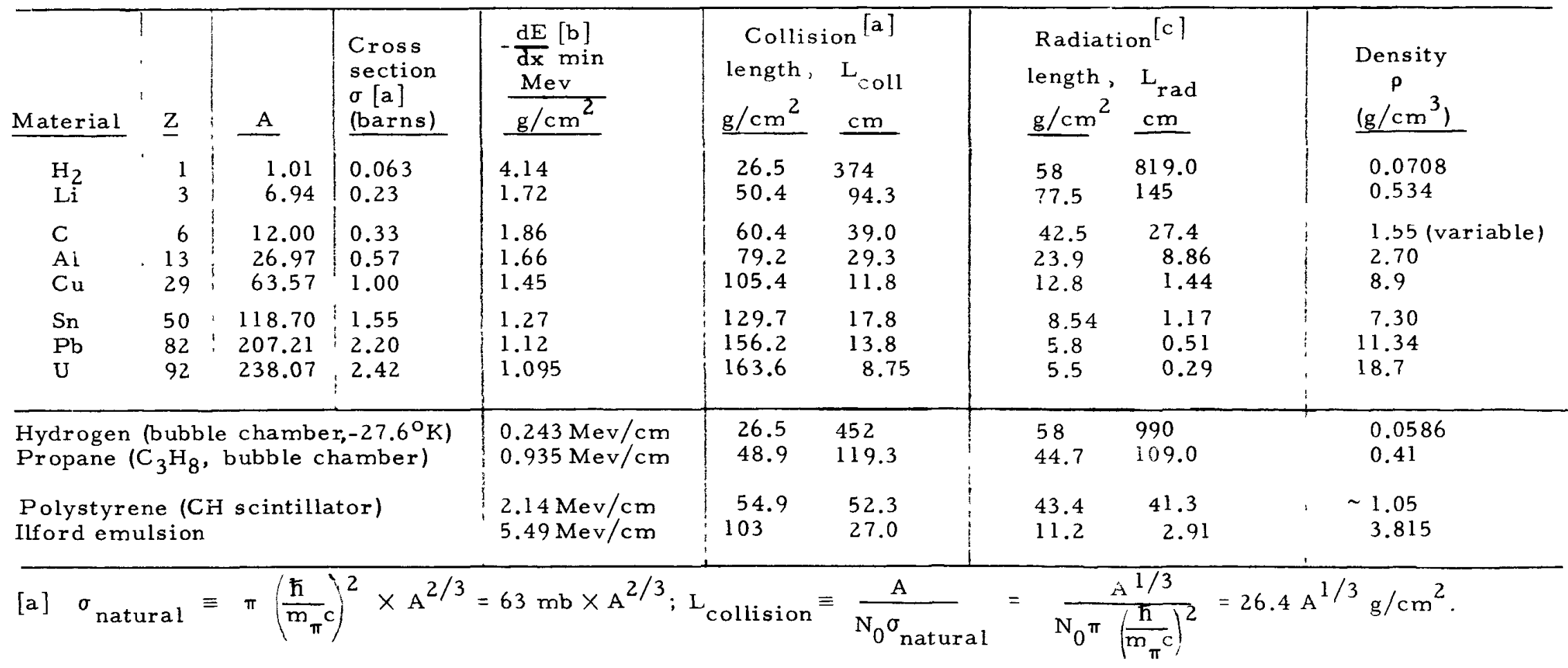

[b] From range-energy tables of M. Rich and R. Madey, UCR L-2301, March 1954, and of Walter H. Barkas, UCR L-3769, April 1957.

[c] From Experimental Nuclear Physics, E. Segrè, Ed. (Wiley, New York, 1953), Table 8, p. 265.

The radiation lengths have not been corrected for failure of the Born approximation and several additional small effects. 


\section{Table III. Particle scattering}

An estimate of multiple Coulomb scattering is often made by assuming that the distribution is Gaussian, with a root-mean-square space angle

$$
\theta_{\mathrm{rms}} \approx(21.2 / \mathrm{Pv}) \sqrt{\mathrm{L} / \mathrm{L}_{\mathrm{rad}}}
$$

where $L$ is the thickness traversed in the scatterer, and $L_{r a d}$ is the radiation length of the scatterer. 8 The equivalent formula for the more useful projected $\mathrm{rms}$ angle is

$$
\theta_{\mathrm{rms}-\mathrm{p}} \approx(15.0 / \mathrm{Pv}) \sqrt{\mathrm{L} / \mathrm{L}_{\mathrm{rad}}}
$$

Although the formula above is convenient, it has the weakness that the true angular distribution is not strictly Gaussian but has an appreciable "tail" out in the region where a Gaussian distribution has fallen to a few percent of its maximum value. 9 This tail (due to single and plural scattering) causes Eq. (1) to be in error by $\sim 20 \%$ for thicknesses $\sim 1 \%$ of a radiation length (it was derived to give correct results for large thicknesses). This error is given in Table III and is discussed below.

Moliere has calculated a distribution that fits the experimental facts, 10 Because of the large "tail" the root-mean-square angles $\theta_{\text {rms }}$ and $\theta_{\text {rms-p }}$ for the Molière distribution are not meaningful unless an arbitrary cutoff angle is introduced. The theory, however, does define a mean (absolute) projected angle of scattering $\theta_{\mathrm{mp}}$.

We have chosen the following way to display the results of Molière's theory. First we have rewritten the familiar Eq. (1) to give the mean projected scattering angle. This was still done on the assumption that the distribution is Gaussian, so that the mean deviation can be obtained from the standard deviation by using the relation $\pi\left(\theta_{\mathrm{rms}-\mathrm{p}}\right)^{2}=2\left(\theta_{\mathrm{mp}}\right)^{2}$. Correcting the 15 in $\mathrm{Eq}$. (lb) by $\sqrt{2 / \pi}$, we then have

$$
\theta_{\mathrm{mp}} \approx(12 / \mathrm{Pv}) \sqrt{\mathrm{L} / \mathrm{L}_{\mathrm{rad}}}
$$

The Molière-theory results are then expressed as correction factors for the crude Eq. (2), i.e., we have expressed the Molière result in the form

$$
\theta_{\mathrm{mp}}=(12 / \mathrm{Pv}) \sqrt{\mathrm{L} / \mathrm{L}_{\mathrm{rad}}}(1+\epsilon) \text {. }
$$

\footnotetext{
$\overline{8}$ See, for example, Reference 5, Eq. (79b).

${ }^{9}$ See, for example, the experimental work of Hansen, Lanzl, Lyman, and Scott, Phys. Rev。84, 634 (1951).

${ }^{10}$ G. Z. Molière, Naturforsch。3 (a), 18 (1948).
} 
The values of the correction $\epsilon$ are compiled in Table III. The root-meansquare formulas, Eq. (1) will also be improved by introducing the factor $(1+\epsilon)$. The estimates of $\epsilon$ in Table III are to be employed with values of Lrad taken from Table II.

The screening effect in the Moliere theory is derived from the Thomas Fermi model of the atom. The error introduced in applying these formulas to the scattering by molecular hydrogen is not known (at least to us).

When the thickness of the scatterer becomes comparable to the nuclear interaction free path in that material, the scattering calculated from Molière's theory will be completely wrong, because specific nuclear scattering will by then have become dominant. Also the high radiation probability makes the theory unusable for electrons except when the foil is thin. Only for muons, therefore, is the formula at all applicable when the absorber is thick. 
Table III

Multiple scattering (Coulomb only) calculated from Molière theory.

$\theta_{\mathrm{mp}}$ is the mean projected angle in radians between tangents to the particle trajectories:

$$
|\theta|_{\text {average }} \equiv \theta_{\mathrm{mp}}=z \frac{12(\mathrm{Mev})}{\mathrm{pv}(\mathrm{Mev})} \sqrt{\frac{\mathrm{L}}{\mathrm{L}_{\mathrm{rad}}}}(1+\epsilon)
$$

$L$ is the thickness, and $L_{r a d}$ the radiation length (from Table II) for the absorber (atomic number $Z$ ). For particles of charge ze and velocity $\beta c$, the following table for $\epsilon$ applies:

\begin{tabular}{|c|c|c|c|c|c|c|}
\hline Z & $10^{-3}$ & $10^{-2}$ & $10^{-1}$ & 1 & 10 & \\
\hline $\begin{array}{r}1 \\
6 \\
29 \\
82\end{array}$ & $\begin{array}{l}-0.20 \\
-0.14 \\
-0.18 \\
-0.27\end{array}$ & $\begin{array}{l}-0.14 \\
-0.07 \\
-0.10 \\
-0.16\end{array}$ & $\begin{array}{l}-0.08 \\
-0.00 \\
-0.01 \\
-0.07\end{array}$ & $\begin{array}{l}-0.03 \\
+0.06 \\
+0.06 \\
+0.02\end{array}$ & $\begin{array}{l}+0.02 \\
+i .12 \\
+0.13 \\
+0.10\end{array}$ & $\begin{array}{l}\beta / z=0.1 \\
(4.7-\mathrm{Mev} \text { proton })\end{array}$ \\
\hline $\begin{array}{r}1 \\
6 \\
29 \\
82\end{array}$ & $\begin{array}{l}-0.26 \\
-0.20 \\
-0.20 \\
-0.28\end{array}$ & $\begin{array}{l}-0.20 \\
-0.12 \\
-0.11 \\
-0.17\end{array}$ & $\begin{array}{l}-0.14 \\
-0.05 \\
-0.03 \\
-0.07\end{array}$ & $\begin{array}{l}-0.08 \\
+0.01 \\
+0.05 \\
+0.08\end{array}$ & $\begin{array}{l}-0.03 \\
+0.07 \\
+0.12 \\
+0.09\end{array}$ & $\begin{array}{l}\beta / z=0.3 \\
(45-\mathrm{Mev} \text { proton) }\end{array}$ \\
\hline $\begin{array}{r}1 \\
6 \\
29 \\
82\end{array}$ & $\begin{array}{l}-0.31 \\
-0.26 \\
-0.25 \\
-0.29\end{array}$ & $\begin{array}{l}-0.24 \\
-0.18 \\
-0.15 \\
-0.17\end{array}$ & $\begin{array}{l}-0.18 \\
-0.10 \\
-0.06 \\
-0.08\end{array}$ & $\begin{array}{l}-0.12 \\
+0.03 \\
+0.02 \\
-0.01\end{array}$ & $\begin{array}{r}-0.07 \\
+0.03 \\
+0.09 \\
+0.09\end{array}$ & $\begin{array}{l}\beta / z=0.7 \\
(380-\text { Mev proton })\end{array}$ \\
\hline $\begin{array}{r}1 \\
6 \\
29 \\
82\end{array}$ & $\begin{array}{l}-0.34 \\
-0.29 \\
-0.34 \\
-0.31\end{array}$ & $\begin{array}{l}-0.26 \\
-0.20 \\
-0.23 \\
-0.19\end{array}$ & $\begin{array}{l}-0.20 \\
-0.12 \\
-0.13 \\
-0.09\end{array}$ & $\begin{array}{l}-0.14 \\
-0.05 \\
-0.05 \\
-0.00\end{array}$ & $\begin{array}{l}-0.08 \\
-0.01 \\
-0.03 \\
-0.08\end{array}$ & $\beta / z=1.0$ \\
\hline
\end{tabular}

* Note that in the Gaussian approximation the root-mean-square projected angle is obtained from the formula above by substituting 15 for the coefficient 12 . 
Table IV. Atomic and nuclear constants

Atomic and nuclear constants in the directly applicable units of Mev, $\mathrm{cm}$, and sec are tabulated. A few useful formulas and numerical constants are also included. 
Table IV

Atomic and nuclear constants in units of $\mathrm{Mev}, \mathrm{cm}$, and sec

GENERAL ATOMIC CONST ANTS

$\mathrm{N}=6.0249 \times 10^{23}$ molecules $/ \mathrm{gram}$

$\mathrm{c}=2.99793 \times 10^{10} \mathrm{~cm} / \mathrm{sec}$

$\mathrm{e}=4.80286 \times 10^{-10} \mathrm{esu}=1.6021 \times 10^{-15}$ coulomb.

$1 \mathrm{Mev}=1.6021 \times 10^{-6} \mathrm{erg}\left[1 \mathrm{ev}=\mathrm{e}\left(10^{8} / \mathrm{c}\right)\right]$

$\hbar=6.5817 \times 10^{-22} \mathrm{Mev} \mathrm{sec}=1.054 \times 10^{-27} \mathrm{erg} \mathrm{sec}$.

$\hbar c=1.9732 \times 10^{-11} \mathrm{Mev} \mathrm{cm}[=\pi$ for $\mathrm{p}=1 \mathrm{Mev} / \mathrm{c}]$

$k=8.6167 \times 10^{-11} \mathrm{Mev} /{ }^{\circ} \mathrm{C}$ [Boltzmann constant]

$a=\frac{\mathrm{e}^{2}}{\hbar c}=1 / 137.037 ; \mathrm{e}^{2}=1.44 \times 10^{-13} \mathrm{Mev} \mathrm{cm}$

QUANTIT IES DERIVED FROM THE ELECTRON MASS, $m$

\section{Mass and Energy}

$\mathrm{m}=0.510976 \mathrm{Mev}=1 / 1836.12 \mathrm{~m}_{\mathrm{p}}=1 / 273.26 \mathrm{~m}_{\pi}$ Rydberg, $R_{\infty}=\frac{\mathrm{me}^{4}}{2 \hbar^{2}}=\mathrm{mc}^{2} \times \frac{\mathrm{a}^{2}}{2}=13.605 \mathrm{ev}$

Length ( 1 fermi $\left.=10^{-13} \mathrm{~cm} ; 1 \AA=10^{-8} \mathrm{~cm}\right)$ $\mathrm{r}_{\mathrm{e}}=\mathrm{e}^{2} / \mathrm{mc}^{2}=2.81785$ fermi

$x_{\text {Compton }}=\frac{\hbar}{\mathrm{mc}}=\mathrm{r}_{\mathrm{e}} \mathrm{a}^{-1}=3.8612 \times 10^{-11} \mathrm{~cm}$

$\mathrm{a}_{\infty \mathrm{Bohr}}=\frac{\hbar^{2}}{\mathrm{me}^{2}}=\mathrm{r}_{\mathrm{e}} \mathrm{a}^{-2}=0.52917 \AA$

Cross Section

$$
\sigma_{\text {Thompson }}=\frac{8}{3} \pi \mathrm{r}^{2}=0.6652 \times 10^{-24} \mathrm{~cm}^{2}=0.6652 \mathrm{barn}
$$

Magnetic Moment and Cyclotron Angular Frequency

$\mu_{\mathrm{Bohr}} \quad=\frac{\mathrm{e} \hbar}{2 \mathrm{mc}}=0.57883 \times 10^{-14} \mathrm{Mev} /$ gauss

$\frac{1}{2} \omega_{\text {cyclotron }}=\frac{\mathrm{e}}{2 \mathrm{mc}}=8.7945 \times 10^{6} \mathrm{rad} \mathrm{sec}^{-1} / \mathrm{gauss}$

$\mathrm{g}_{\text {electron }}=2\left[1+\frac{\mathrm{a}}{2 \pi}+0.328\left(\frac{\mathrm{a}}{\pi}\right)^{2} 1=2[1.001163]^{\mathrm{b}}\right.$

$g_{\text {muon }}=2\left[1+\frac{a}{2 \pi}+0.75\left(\frac{a}{\pi}\right)^{2} 1=2[1.001172]^{b}\right.$

QUANTITIES DERIVED FROM THE PROTON MASS, $m_{p}$ Rest mass $=938.211 \mathrm{Mev} / \mathrm{c}^{2}=1836.12 \mathrm{~m}_{\mathrm{e}}=6.719 \mathrm{~m}_{\pi}$ $1.007593 \mathrm{~m}_{1}\left(\mathrm{~m}_{1}=1 \mathrm{amu}=\frac{1}{16} \mathrm{O}^{16}\right)$

Magnetic Moment and Cyclotron Angular Frequency

$\mu_{\mathrm{p}} \quad=\frac{\mathrm{e} \hbar}{2 \mathrm{~m}_{\mathrm{p}} \mathrm{c}}=3.1524 \times 10^{-18} \mathrm{Mev} /$ gauss

$\frac{1}{2} \omega_{\text {cyclotroñ }}=\frac{\mathrm{e}}{2 \mathrm{~m}_{\mathrm{p}} \mathrm{c}}=4.7896 \times 10^{3} \mathrm{rad} \mathrm{sec}^{-1} / \mathrm{gauss}$

$\left.\left.\mathrm{g}_{\mathrm{p}} \equiv \frac{\mu}{\mu_{\mathrm{p}}}\right)_{\text {proton }}=2.79275 ; \quad \mathrm{g}_{\mathrm{n}} \equiv \frac{\mu}{\mu_{\mathrm{p}}}\right)_{\text {neutron }}=-1.9128$ 
Table IV (continued)

QUANTITIES DERIVED FROM THE MASS OF THE

CHARGED PION, $\mathrm{m}_{\pi}$

$\underline{\text { Rest mass }}=139.63 \mathrm{Mev} / \mathrm{c}^{2}=273.26 \mathrm{~m}_{\mathrm{e}}=0.14882 \mathrm{~m}_{\mathrm{p}}$

Length

$$
\frac{\hbar}{\mathrm{m}_{\pi} \mathrm{c}}=1.4132 \text { fermi }(\sim \sqrt{2} \text { fermi })
$$

Natural ( $\approx$ "geometrical") Nucleon Cross Section

$\pi\left(\frac{\hbar}{m_{\pi} c}\right)^{2}=62.7344 \mathrm{mb}\left(1 \mathrm{mb}=10^{-27} \mathrm{~cm}^{2}\right)$

\section{$(3 / 2,3 / 2) \pi \mathrm{p}$ Resonance}

Center-of-mass momentum: $\mathrm{p}_{\pi}=230 \mathrm{Mev} / \mathrm{c}$

Lab-system momentum: $\mathrm{P}_{\pi}=303 \mathrm{Mev} / \mathrm{c}\left(\mathrm{T}_{\pi}=194 \mathrm{Mev}\right)$ RADIOACT IVIT Y

1 curie $=3.7 \times 10^{10}$ disintegrations $/ \mathrm{sec}$

$$
1 \mathrm{r} \quad=87.8 \mathrm{ergs} / \mathrm{g} \text { air }=5.49 \times 10^{7} \mathrm{Mev} / \mathrm{g} \text { air }
$$

Fluxes (per $\mathrm{cm}^{2}$ ) to liberate $1 \mathrm{r}$ in carbon: $3 \times 10^{7}$ minimum ionizing singly charged particles $0.9 \times 10^{9}$ photons of 1 Mev energy.

(These fluxes are are actually correct to within a factor of two for all materials.)

Natural background: $100 \mathrm{mr} /$ year

"Tolerance" 100 millirem/week [Note, $1 \mathrm{r}$ may produce up to 10 "rem" ( $r$ equivalent for man), depending on type of radiation. ]

\section{MISCELLANEOUS}

Physical Constants

1 year $=3.1536 \times 10^{7} \mathrm{sec}\left(\approx \pi \times 10^{7} \mathrm{sec}\right)$

Density of air $=1.205 \mathrm{mg} / \mathrm{cm}^{3}$ at $20^{\circ} \mathrm{C}$

Acceleration by gravity $=980.67 \mathrm{~cm} / \mathrm{sec}^{2}$

1 calorie $=4.184$ joules

1 atmosphere $=1033.2 \mathrm{~g} / \mathrm{cm}^{2}$

\section{Numerical Constants}

1 radian $=57.29578 \mathrm{deg} ; \mathrm{e}=2.71828$

$\ln 2=0.69315 ; \log _{10} \mathrm{e}=0.43429 ;$

$\ln 10=2.30259 ; \log _{10} 2=0.30103$.

Stirling's approximation

$\sqrt{2 \pi n}\left(\frac{n}{e}\right)^{n}<n !<\sqrt{2 \pi n}\left(\frac{n}{e}\right)^{n}\left(1+\frac{1}{12 n-1}\right)$

Gaussianlike Distributions

For $n>-1$ but not necessarily integral:

$$
\int_{0}^{\infty} x^{2 n+1} \exp \int_{2 \sigma^{2}} \cdot d x=2^{n} n ! \sigma^{2 n+2} ;\left(\frac{1}{2}\right) !=\sqrt{ } \pi / 2
$$

Relation between standard deviation $\sigma$ and mean deviation a:

$2 \sigma^{2}=\pi a^{2} ; \sigma=1.4826$ probable error.

Odds against exceeding one standard deviation $=2.15: 1$; two, 21:1; three, 370:1; four, 16,000:1;

five, $1,700,000: 1$

${ }^{\mathrm{a}}$ Based mainly on Cohen, Crowe, and Dumond, The Fundamental Constants of Physics(Interscience, New York, 1957 ).

${ }^{\mathrm{b}} \mathrm{C}$. Sommerfield, Phys. Rev. 107, 328 (1957). 
Table V. Particle decay and reaction dynamics

Energy and momentum conservation have been applied to the possible decay reactions of the unstable particles listed in Table I, and center-ofmass quantities of interest derived from the mass values listed are given in. Table Va. Reactions of negative particles with protons and deuterons have also been analyzed and the results are given in Table $\mathrm{Vb}$.

Coulomb binding energies have been neglected. The tables were prepared before the: final estimate of the $\Sigma^{0}$ mass was made and the figure used for this mass was 1190.0 rather than $1190.5 \mathrm{Mev}$. The number of significant figures is correctly given for the particle masses, but other table entries may contain more than are experimentally justified. 


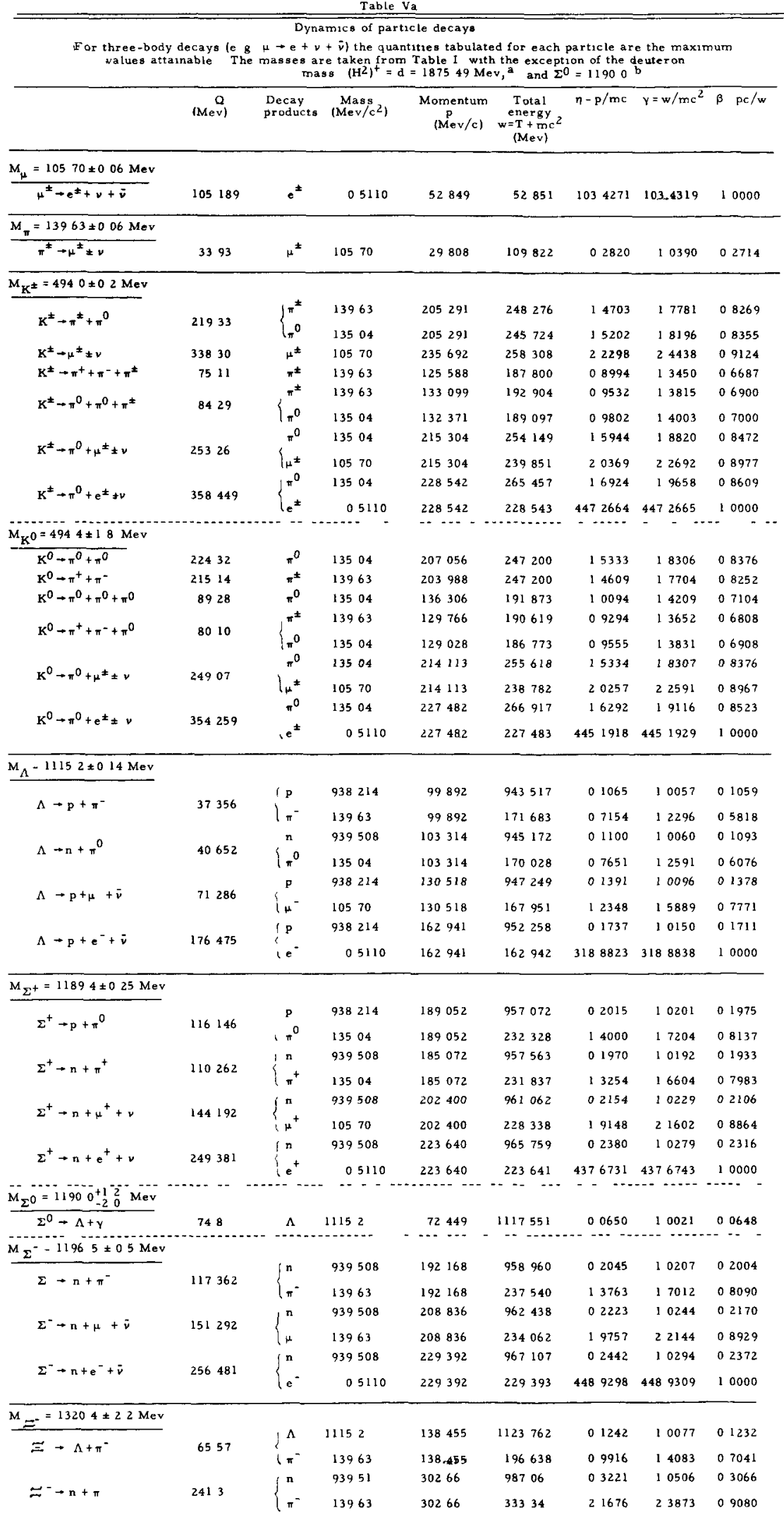

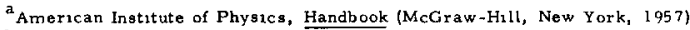
${ }^{b}$ See Ref (p) of Table I 
Table $\mathrm{Vb}$

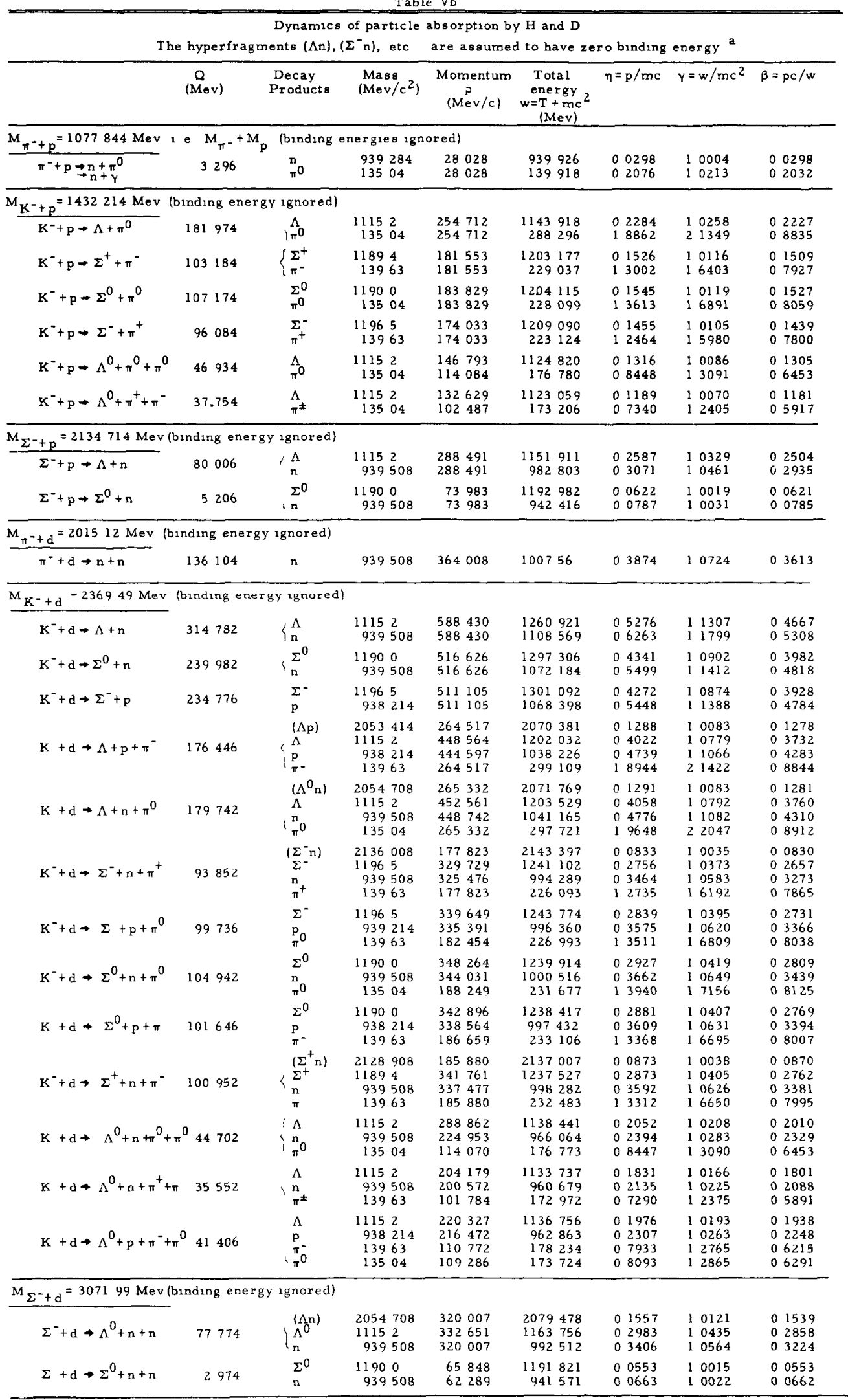

${ }^{a}$ Note that the $\Sigma^{0}$ mass was assumed to be 11900 Mev for this table See ref (p) of Table I 
Figure 1. Range and energy-loss rate

The curves labeled $R_{a}, R_{p}$, etc., are the ranges of alpha particles, protons, etc., in $\mathrm{g} / \mathrm{cm}^{2}$ of Ilford $\mathrm{P}^{2}$ mulsion plotted vs kinetic energy. The energy-loss rate $\mathrm{dE} / \mathrm{dx}$ for protons has also been included. Provided thicknesses are measured in $\mathrm{g} / \mathrm{cm}^{2}$, the range curves also apply for all other materials (except $\mathrm{H}_{2}$ ) with an error usually not exceeding $30 \%$. The conversion from $\mathrm{cm}$ of emulsion to $\mathrm{g} / \mathrm{cm}^{2}$ was made on the as sumption of a standard emulsion density of $3.815 \mathrm{~g} / \mathrm{cm}^{3}$.

The electron "range" curve becomes meaningless as the "critical energy" is approached. The critical energy is defined as that energy at which radiation and ionization are equally important; for example, this occurs at about $15 \mathrm{Mev}$ in emulsion. The electron range curve is not drawn above this energy. Where drawn, it is taken from experimental data, so that radiation is crudely taken into account. These ranges apply "along the track" (i.e., correcting for Coulomb scattering). In practice (for example, for low-energy electrons) the projected range may be much smaller than given by the curve.

The mean free path ("L $L_{\text {collision }}$ ") has been indicated, because, except for $R_{\mu}$, the range is not very meaningful when it is large in comparison with this distance.

The equality of ranges of singly charged particles at a common energy of about $3 \mathrm{Bev}$ is to be noted.

A simple analytical expression for the range in $\mathrm{g} / \mathrm{cm}^{2}$ for a particle of charge $\mathrm{ze}$, mass number $\mathrm{A}$, and kinetic energy $\mathrm{T}$ in a stopping material of atomic number $\mathrm{Z}$ (excluding hydrogen) is

$$
\mathrm{R}=\frac{\mathrm{z}^{0.26} \mathrm{~T}^{1.7}}{500 \mathrm{z}^{2} \mathrm{~A}^{0.7}} \mathrm{~g} / \mathrm{cm}^{2} \text {; }
$$

this is correct to within about $10 \%$ for T/A from 1 Mev to $400 \mathrm{Mev}$. For protons it is simply

$$
\mathrm{R}=\frac{\mathrm{z}^{0.26} \mathrm{~T}^{1.7}}{500} \mathrm{~g} / \mathrm{cm}^{2}
$$




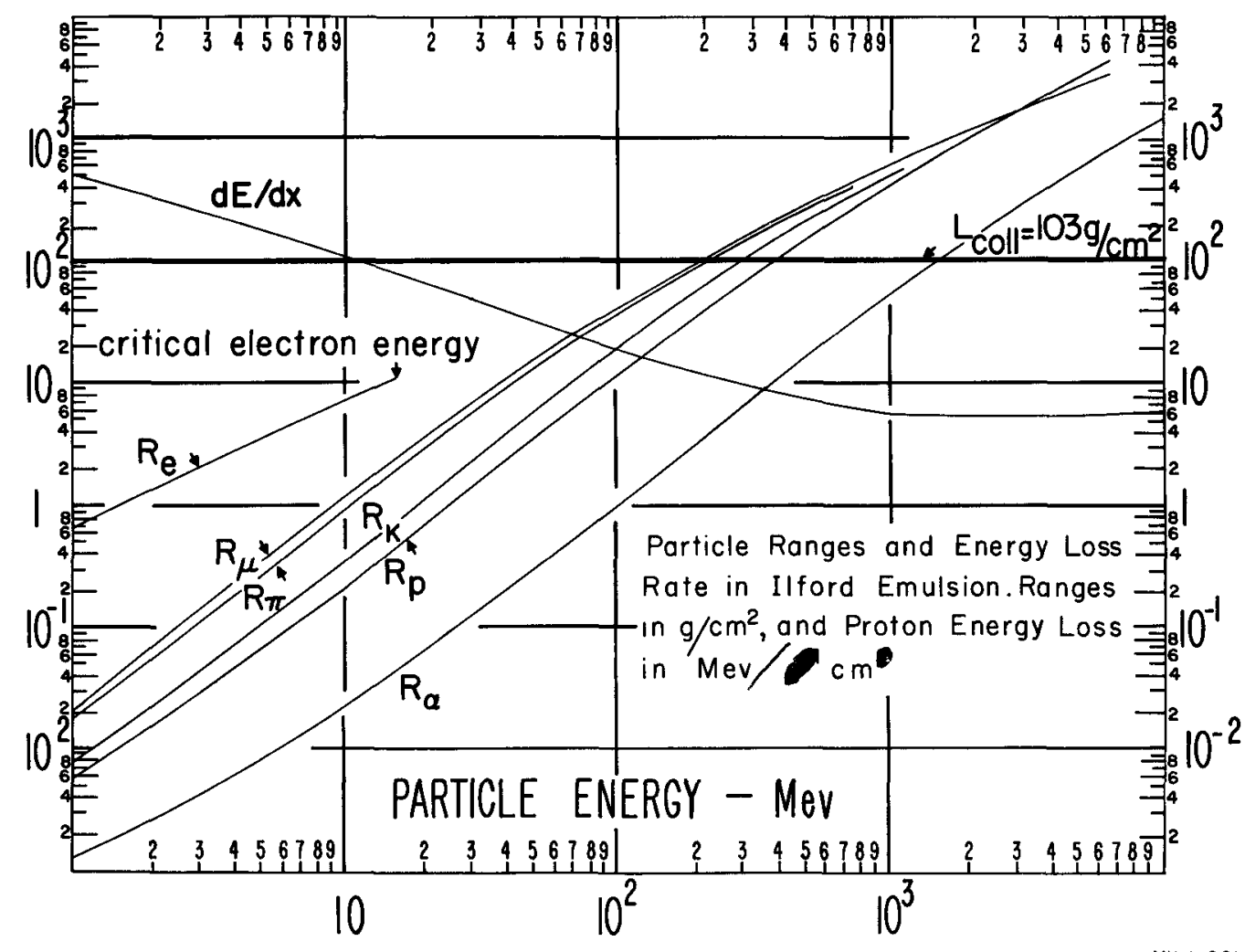

Fig. 1 


\section{ACKNOW LEDGMENTS}

We are much obliged to Jon Peter Berge and Louise Holstein for their aid in computing the tables.

There may remain errors and oversights in the tables or text. We should be most grateful to have such faults called to our attention, and to receive suggestions for improving the usefulness of the tables.

This work was done under the auspices of the U. S. Atomic Energy. Commission.

Information Division

sa 